\title{
MANAJEMEN PERSATUAN BOLA BASKET SELURUH INDONESIA (PERBASI) KABUPATEN TANGGAMUS
}

\author{
Joan Siswoyo*1, Ardian Cahyadi², Lungit Wicaksono $^{3}$ \\ Universitas Lampung, Indonesia ${ }^{* 1,2,3}$ \\ Email: joan.siswoyo@fkip.unila.ac.id"1 ${ }^{*}$, ardian.cahyadi@fkip.unila.ac.id ${ }^{2}$, \\ lungit.wicaksono02@fkip.unila.ac.id ${ }^{3}$
}

Received: 30 June 2020; Accepted 10 October 2020; Published 08 December 2020

Ed 2020; 5(2): 215-225

\begin{abstract}
ABSTRAK
Penelitian ini bertujuan untuk menghasilkan: (1) Model pelaksanaan program manajeman di PERBASI Kabupaten Tanggamus, (2) Model sistem manajemen dan pembinaan bola basket di PERBASI Kabupaten Tanggamus. Penelitian ini adalah penelitian kualitatif. Subjek penelitian ini adalah: (1) Pengkab PERBASI Tanggamus (2) Pengurus PERBASI Tanggamus (3) Instansi olahraga yang berada di lingkungan Kabupaten Tanggamus, (4) atlet, pelatih, masyarakat. Pengumpulan data menggunakan observasi, wawancara dan dokumentasi. Teknik analisis data yang digunakan adalah triangulasi. Hasil penelitian menunjukan bahwa: (1) Pengkab PERBASI dalam menjalankan manajemen organisasi belum memiliki sistem dalam melaksanakan program, (2) Sistem pembinaan bola basket di Tanggamus belum terprogram secara berkelanjutan, (3) Sistem pembinaan olahraga di Tanggamus kurang berjalan maksimal. Sistem manajemen organisasi, bola basket dan olahraga di Kabupaten Tanggamus belum berjalan dengan baik. Berdasarkan hasil penelitian, peneliti mengajukan model ideal manajeman olahraga (1) Model Ideal Pelaksanaan Manajemen Bola Basket di PERBASI Tanggamus, (2) Model ideal sistem manajemen. Kesimpulan hasil penelitian menyatakan pelaksanaan manajemen dan pembinaan olahraga bola basket di Kabupaten Tanggamus belum berjalan secara terprogram. Saran dari peneliti bahwa semua pihak yang terkait dalam sebuah sistem pembinaan olahraga bola basket di Kabupaten Tanggamus agar bekerjasama melaksanakan program manajemen.
\end{abstract}

Kata Kunci: Manajemen; Sistem Pembinaan; Bola Basket

\section{MANAGEMENT OF INDONESIAN BASKETBALL ASSOCIATION (PERBASI) IN TANGGAMUS DISTRICT}

\begin{abstract}
This study aims to produce: (1) Model of management program implementation in PERBASI (Indonesian Basketball Association) Tanggamus Regency, (2) Model of management system and basketball coaching in PERBASI Tanggamus Regency. This is a qualitative research study looking at different aspects of sport organization in this region. The research subjects are: (1) Branch manager of PERBASI Tanggamus (2) Manager of PERBASI Tanggamus (3) Sports agencies in the Tanggamus Regency, (4) athletes, coaches, communities. Data collection was performed by using observation, interviews and documentation. The data analysis technique used was triangulation. The results showed that: (1) Branch manager of PERBASI in carrying out organizational management does not have a system of implementing the program, (2) The basketball coaching system at Tanggamus has not been designed to be sustainable, (3) The sports coaching system at Tanggamus is not running optimally. The management system of the organization, basketball and sports in Tanggamus Regency is not yet running well. Based on the results, it proposes an ideal model of sports management (1) the ideal model of basketball management in PERBASI Tanggamus, (2) the ideal model of a management system. The conclusion of the research states that the implementation of basketball management and coaching in Tanggamus Regency has not been programmed efficiently. Results of this research suggest that all parties involved in a basketball sports coaching system in Tanggamus Regency should cooperate in implementing management programs.
\end{abstract}

Keywords: Management; Coaching System; Basketball

Copyright (C2020, Journal Sport Area

DOI: https://doi.org/10.25299/sportarea.2020.vol5(2).5219 
How To Cite: Siswoyo, J., Cahyadi, A., \& Wicaksono, L. (2020). Manajemen Persatuan Bola Basket Seluruh Indonesia (PERBASI) Kabupaten Tanggamus. Journal Sport Area, 5(2), 215-225.

\section{PENDAHULUAN}

Pembinaan dan pengembangan olahraga adalah usaha sadar yang dilakukan secara sistematis untuk mencapai tujuan keolahragaan (Undang-Undang Republik Indonesia, 2005), dan salah satu tujuan keolahragaan adalah peningkatan prestasi olahraga. Pencapaian prestasi diperlukan adanya pembinaan sedini mungkin melalui pencarian dan pemantauan bakat, pembibitan, pendidikan dan pelatihan olahraga yang didasarkan pada ilmu pengetahuan dan teknologi secara lebih efektif serta peningkatan kualitas organisasi olahraga baik tingkat pusat maupun daerah. Menurut Rumini (2015) pembinaan prestasi adalah usaha sistematis yang dilakukan guna memeroleh hasil yang lebih baik dalam meraih prestasi. Pembinaan yang dilakukan akan sesuai dengan harapan apabila dilaksanakan secara efisien, sitematik, dan berkelanjutan, karena suatu proses pembinaan olahraga membutuhkan waktu yang lama (Nugraha \& Pratama, 2019). Faktor pembinaan yang diberikan melalui program manajemen dan pembinaan yang terstruktur dan berkelanjutan dengan konsep yang baik akan menjadi tujuan prestasi pada ajang cabang tertentu sebagai penjaringan bagi atlet berprestasi dalam meningkatkan harkat dan martabat sebagai individu maupaun negara di iven Internasional (Dongoran, Kalalo, \& Syamsudin, 2020).

Menurut Saputra dan Subagio (2016) menyatakan olahraga prestasi adalah kegiatan olahraga yang membina dan mengembangkan secara terencana, berjenjang, dan berkelanjutan melalui kompetisi untuk mencapai prestasi dengan dukungan ilmu pengetahuan dan teknologi keolahragaan dan juga harus memiliki kebugaran jasmani yang baik serta keterampilan di atas kemampuan non atlet. Muryadi (2015) menjelaskan bahwa untuk mencapai prestasi puncak dalam olahraga diperlukan latihan jangka panjang kurang lebih 8-10 tahun yang dilakukan secara kontinyu, bertahap, meningkat dan berkesinambungan. Pencapaian prestasi maksimal tidak lepas dari pihak-pihak yang sangat berkepentingan terhadap hal tersebut antara lain meliputi: pembina olahraga (pelatih, pengurus induk organisasi keolahragaan seperti: KONI, PB/PP, Pengda, Pengcab klub), atlet, masyarakat yang mendukung perkembangan basket.

Permasalahan yang terjadi di PERBASI Kabupaten Tanggamus Sejak tahun 2014 prestasi pertama yang diraih adalah peringkat ke 3 kompetisi PORPROV yaitu mendapat medali perunggu dan hanya 1 orang atlet bernama Ahmed Auzar dan terpilih sebagai salah satu pemain yang memperkuat tim Lampung di Pekan Olahraga Antar Wilayah (PORWIL) di tahun 2016. Sampai tahun 2019 belum ada pemain dari Kabupaten Tanggamus yang dipilih untuk mewakili Lampung di ajang nasional. Prestasi PERBASI Kabupaten Tanggamus Provinsi Lampung tidak dapat mempertahankan dan meningkatkan prestasinya dari tahun ke tahun bahkan mengalami penurunan prestasi terutama dalam kompetisi PORPROV. Dari hasil pembinaan yang dilakukan selama ini, klub tidak mampu melahirkan atlet-atlet basket di Kabupaten Tanggamus Provinsi Lampung yang mampu mempersembahkan prestasi di tingkat daerah maupun nasional.

Menurut Handoko (2011) manajemen yang baik itu jika terdapat di dalamnya fungsi manajemen seperti: (1) perencanaan, (2) pengorganisasian, (3) pengarahan, (4) pengawasan. Apabila fungsi-fungsi itu dilaksanakan dalam suatu manajemen maka manajemen tersebut dapat dikatakan baik. Secara konseptual, fungsi tersebut sangat penting bagi pelaksanaan proses pembinaan olahraga berskala nasional atau mikro level klub. Muslima dan Himam (2018) mengatakan pencapaian prestasi olahraga merupakan hasil kerja yang membutuhkan kesiapan dari segala bidang seperti kesiapan program 
latihan (perencanaan), kesiapan sarana dan prasarana, kesiapan pelatih untuk melatih, kesiapan atlet untuk melaksanakan program pelatihan dan ketersediaan dukungan dari lingkungan.

Tujuan manajemen PERBASI Kabupaten Tanggamus Provinsi Lampung adalah untuk memperoleh gambaran yang menyeluruh tentang proses pelaksanaan manajemen PERBASI Kabupaten Tanggamus Provinsi Lampung, serta mendeskripsikan manajemen pendanaan sarana dan prasarana yang ada, pelatih, pelaksanaan program latihan yang dibuat, kepengurusan, atlet dan dukungan masyarakat di lingkungan agar dapat dievaluasi dan diperbaiki secara menyeluruh. Tugas serta tanggung jawab Pemerintah Provinsi dalam mendukung kegiatan Kabupaten/Kota untuk menciptakan prestasi di bidang olahraga yaitu dalam bekerjasama harus melibatkan KONI Provinsi, KONI Kabupaten/Kota dibidang olahraga prestasi, dan pembinaan olahraga pendidikan menjadikan kewenangan Dinas Pendidikan dan Dinas Pemuda dan Olahraga. Dalam pelaksanaannya yang harus dilakukan dan saling bekerjasama dalam hal berikut: (1) melaksanakan dan menjalankan kebijakan serta program olahraga prestasi, olahraga pendidikan, dan olahraga rekreasi di daerah, (2) melakukan pemberdayaan, kerjasama kepada masyarakat, pemberdayaan dukungan dunia usaha untuk bidang olahraga prestasi, olahraga pendidikan, dan olahraga rekreasi, (3) memberikan pelatihan dan penataran langsung sumber daya manusia daerah (Provinsi, Kabupaten/Kota) untuk mendukung peningkatan kualitas keolahragaan secara keseluruhan, (4) memberdayakan potensi sumber daya daerah (Provinsi, Kabupaten/Kota), termasuk kekayaan alam dan budaya asli daerah, (5) mendukung dan meningkatkan penerapan dan pemanfaatan ilmu pengetahuan dan teknologi di daerah, (6) menyelenggarakan kompetisi daerah maupun nasional, (7) meningkatkan kualitas manajemen organisasi olahraga (pendidikan, rekreasi, prestasi) daerah, (8) menyediakan serta perlindungan fasilitas olahraga baik yang dimiliki pemerintah maupun masyarakat.

Ramadan dan Iskandar (2018) menyatakan bahwa prestasi olahragapun berjalan lurus dengan fasilitas selama proses latihan serta semakin mendukung fasilitas yang diberikan akan bejalan lurus dengan prestasi yang diraih. Karena menurut Laksana (2017) menyatakan prestasi olahraga merupakan faktor yang dapat meningkatkan harkat dan martabat bangsa di mata dunia. Ada empat komponen utama manajemen (POAC) yakni perencanaan (planning), pengorganisasian (organizing), pergerakan (actuating), dan pengawasan (controlling) sudah dikatakan baik karena berjalan sesuai sistem dan aturan empat komponen utama manajemen (POAC) (Rachmawati, Kriswantoro, \& Nasution, 2019).

Beberapa strategi yang dapat dibandingkan dan dapat dilakukan oleh PERBASI Kabupaten Tanggamus Provinsi Lampung sebagai tujuan visi dan misi ke depan dan apabila beberapa komponen manajeman tidak dilakukan maka akan mengubah kinerja dari PERBASI Kabupaten Tanggamus Provinsi Lampung. Ulum, Setyawati, dan Yuwono (2013) dalam penelitiannya menemukan bahwa: (1) pembinaan prestasi atlet wushu di sasana wushu se-Kota Salatiga cukup baik, (2) keadaan organisasi sudah berjalan dengan baik, baik dari WI dan sasana yang masih menjalankan pembinaan saat ini karena terkoordinir dengan baik, masih bersifat sederhana, kekeluargaan dan keterbukaan antar anggotanya, (3) kualitas pelatih sudah bagus tetapi perlu penambahan pelatih.

Tujuan dari penelitian ini yaitu dalam pelaksanaan 4 komponen manajeman (POAC) Kabupaten Tanggamus dapat diaplikasikan serta membuat model alternatif manajeman yang baik agar PERBASI Kabupaten Tanggamus bisa mendapatkan prestasi yang jauh 
lebih baik. Dalam menunjang kegiatan POAC, manajeman organisasi yang dilakukan dalam hal pembinaan prestasi perlu adanya dukungan baik pendanaan, sarana dan prasarana sebagai bentuk dari proses kegiatan pembinaan. Kesimpulanya adalah tanpa adanya dukungan maka tidak akan maksimal dalam menjalankan pembinaan, serta dukungan tersebut sangat terkait untuk program terpadu dalam mendukung seluruh kegatan olahraga sehingga prestasi dapat tercapai. Pembinaan olahraga perlu dukungan yang tidak sedikit, oleh karena itu sistem pembinaan melibatkan seluruh sistem dan jajaran yang ada di Kabupaten Tanggamus.

\section{METODE PENELITIAN}

Metode penelitian dalam penelitian ini adalah deskriptif kualitatif. Dari permasalahan yang diteliti bertujuan untuk dapat visualisasikan dan menjabarkan secara jelas keadaan yang sesungguhnya tentang kondisi yang ada dan proses penelitian untuk memahami masalah manusia serta sosial, berdasarkan pada tatanan yang kompleks, gambaran yang holistik, disusun dengan kata-kata, melaporkan pandangan detail para informan dan dilaksanakan pada latar alamiah atau natural.

Data yang digunakan dalam penelitian ini meliputi: (1) Paper: Dokumen tentang Pengkab PERBASI Kabupaten Tanggamus Provinsi Lampung, dokumen atlet, dokumen pelatih, majalah, buku-buku dan lainnya, (2) Place: Tempat latihan, sarana dan prasarana, kegiatan latihan, (3) Person: Pengurus, pelatih, atlet dan tenaga penunjang. Guna memperoleh data primer dalam penelitian ini digunakan alat pengumpul data berupa, observasi, pedoman wawancara, sedangkan dokumentasi berupa arsip yang digunakan sebagai data pendukung atau data sekunder. Instrumen inilah yang digunakan untuk memperoleh data tentang program manajemen kerja Pengkab PERBASI Kabupaten Tanggamus Provinsi Lampung.

Subjek penelitian dan data yang akan dicari adalah manajemen yang ada di PERBASI Kabupaten Tanggamus Provinsi Lampung. Semua data yang menggambarkan pelaksanaan proses manajemen, sehingga data yang akan diperoleh harus diamati secara langsung di lapangan, untuk itu di dalam proses penelitian ini peneliti harus langsung mengumpulkan data dalam situasi yang sesungguhnya. Dalam penelitian ini yang menjadi responden atau subyek penelitian sejumlah 10 orang yang terdiri dari: (1) 2 orang Pengurus PERBASI Tanggamus, (2) 2 orang Pelatih, (3) 2 orang Atlet, (4) 2 orang Orang tua atlet, (5) 1 orang KONI Tanggamus, (6) 1 orang Dispora Tanggamus. Keabsahan data dalam penelitian ini dilakukan dengan dua cara yaitu: (1) Teknik Triangulasi, teknik ini digunakan untuk keperluan pengecekan atau pembanding terhadap data tersebut, (2) Teknik Pengamatan, teknik ini digunakan untuk memperoleh data yang akurat dan sahih.

\section{HASIL DAN PEMBAHASAN}

Hasil penelitian terkait dengan manajeman meliputi fungsi manajemen yang terdiri perencanaan (planning), pengorganisasian (organizing), staffing, pengarahan (leading), pengawasan (controlling) (Miles, Huberman, \& Saldana, 2014). Pengkab PERBASI Tanggamus Provinsi Lampung harus memiliki semua fungsi dalam hal manajemen.

Tabel 1. Fungsi Manajemen PERBASI Kabupaten Tanggamus

\begin{tabular}{ccc}
\hline No & $\begin{array}{c}\text { Fungsi } \\
\text { Manajeman }\end{array}$ & Temuan Pelaksanaan \\
\hline
\end{tabular}




\begin{tabular}{|c|c|c|}
\hline 1 & $\begin{array}{c}\text { Perencanaan } \\
\text { (Planning) }\end{array}$ & $\begin{array}{l}\text { a. Sudah ada tetapi tidak dilaksanakan dengan baik, karena } \\
\text { keterbatasan dana dan dukungan dari pemerintah daerah sangat } \\
\text { kurang terlihat pada program kerja tahun } 2017 \text {. } \\
\text { b. Program kerja tidak dilaksanakan dengan baik dan dari semua } \\
\text { pengurus yang terdapat di Pengkab PERBASI Tanggamus } \\
\text { c. Tidak ada tindak lanjutnya apakah akan diperbaiki atau tidak, } \\
\text { ini } \\
\text { d. Sikap perencanaan yang baik tetapi tidak dilaksanaakan dan } \\
\text { dijalankan dengan baik }\end{array}$ \\
\hline 2 & $\begin{array}{c}\text { Pengorganisasia } \\
\mathbf{n} \\
(\text { Organizing })\end{array}$ & $\begin{array}{l}\text { Kurang baik dalam beberapa hal seperti: } \\
\text { a. Cara manajemen merancang struktur formal untuk penggunaan } \\
\text { sumber daya keuangan, fisik, atlet, dan tenaga kerja organisasi } \\
\text { kurang efektif. } \\
\text { b. Hubungan-hubungan antara fungsi jabatan, tugas dan para } \\
\text { karyawan kurang baik. } \\
\text { c. Serta cara dimana para ketua lebih lanjut memantau tugas-tugas } \\
\text { yang harus dilaksanakan dalam organisasi mereka dan } \\
\text { mendelagasikan wewenang yang diperlukan untuk } \\
\text { mengerjakan tugas tersebut. }\end{array}$ \\
\hline 3 & $\begin{array}{c}\text { Penyusunan } \\
\text { keanggotaan } \\
\text { (Staffing) }\end{array}$ & $\begin{array}{l}\text { a. Tidak adanya koordinasi dan kesepakatan yang baik dari pihak } \\
\text { yang lebih tinggi dalam organisasi membuat struktur Pengkab } \\
\text { PERBASI Tanggamus dan nama pengurus yang mendapat } \\
\text { tugas sebagai bagian pengurus, tidak berjalan dengan baik } \\
\text { b. Tidak tahu fungsi dan kerja mereka didalam organisasi } \\
\text { Pengkab PERBASI Tanggamus. } \\
\text { c. Penempatan seseorang didalam kepengurusan Pengkab } \\
\text { PERBASI Tanggamus banyak tidak tepat dan banyak yang } \\
\text { tidak sesuai bidangnya. }\end{array}$ \\
\hline 4 & $\begin{array}{l}\text { Pengarahan } \\
\text { memimpin } \\
\text { (Leading) }\end{array}$ & $\begin{array}{l}\text { a. Ketidakpahaman di beberapa posisi di kepengurusan Pengkab } \\
\text { PERBASI Tanggamus, } \\
\text { b. ketua harian PERBASI Tanggamus saat ini hanya mengetahui } \\
\text { dan menyetujui apa rancangan yang dibuat oleh kesepakan dari } \\
\text { bidang pembinaan SDM dan bidang pengembangan prestasi. }\end{array}$ \\
\hline 5 & $\begin{array}{l}\text { Pengawasan } \\
\text { (Controlling) }\end{array}$ & $\begin{array}{l}\text { a. Kurang perhatian dalam laporan pertanggungjawaban oleh } \\
\text { segenap pengurus dan pelatih, akibatnya ada penyelewengan } \\
\text { atau pelanggaran penggunaan dana, } \\
\text { b. Tidak ada melakukan audit, transparansi, dan unsur kepedulian } \\
\text { sesama anggota untuk diajak bekerja sama untuk menjalankan } \\
\text { tugas sesuai bidangnya. }\end{array}$ \\
\hline
\end{tabular}

Beberapa hasil penelitian menunjukkan bahwa manajemen pembinaan olahraga berpengaruh pada pencapaian prestasi atlet (Rachmawati et al., 2019; Wani, 2018; Wen, 2015; Yusfi \& Mashuri, 2019). Beraan, Karim, dan Irawan (2019) menunjukkan bahwa perencanaan (planning) manajemen pembinaan olahraga prestasi dilakukan melalui proses penyusunan program strategis KONI. Pengorganisasian (organizing) dilakukan dengan melakukan koordinasi dan kerjasama dengan pengurus daerah seluruh kegiatan olahraga tingkat daerah, nasional dan internasional dan Peran jaringan mencakup kerjasama antar organisasi penting dalam memfasilitasi perolehan sumber daya (Misener \& Doherty, 2013). Pelaksanaan (actuating) dilakukan melalui pembinaan atlet secara berjenjang, simultan dan sistematis dan penilaian pelatih yang memadai diperlukan untuk memperoleh implikasi manajerial yang akurat (Swierzy, Wicker, \& Breuer, 2019). 
Pengawasan (controlling) dengan membentuk Tim Monitoring dan Evaluasi (Tim Monev). Pemanfaatan teknologi dalam kursus manajemen olahraga menyajikan gambaran pemanfaatan teknologi dalam pendidikan tinggi, hubungan antara teknologi danproses pembelajaran, dan perlunya menerapkan teknologi dalam kursus manajemen olahraga (Carkanji \& Bozo, 2012). Schaillee, Spaaij, Jeanes, dan Theeboom (2019) mengungkapkan kendala individu, organisasi, dan eksternal yang perlu diakui danjika memungkinkan, dikelola. Serta menurut Robertson, Eime, dan Westerbeek (2018), untuk menjadi organisasi olahraga yang bertanggung jawab secara sosial, fokus organisasi harus berada pada memenuhi kewajiban yang bermakna dan berdampak pada masyarakat.

Pembahasan penelitian memperoleh gambaran yang menyeluruh tentang proses pelaksanaan manajemen PERBASI Kabupaten Tanggamus Provinsi Lampung, sehingga bisa mendeskripsikan seluruh fungsi dan kegiatan yang ada di PERBASI Kabupaten Tanggamus yaitu, pelaksanaan manajemen PERBASI Tanggamus, pembinaan basket pada Pengkab, dan pembinaan olahraga secara umum di Kabupaten Tanggamus menggambarkan bahwa Manajemen PERBASI Tanggamus perlu untuk dibenahi kekurangnya berdasarkan fungsi manajemen yang menjadi pokok masalah dalam perencanaan, pengorganisasian, penyusunan kinerja, pengarahan, dan pengawasan serta dikembangkankan kelebihannya, sehingga PERBASI Tanggamus bisa menjadi dasar solusi yang baik dalam tahap pembinaan yang berjenjang.

Tabel 2. Program Manajemen PERBASI Kabupaten Tanggamus

\begin{tabular}{|c|c|c|c|}
\hline $\begin{array}{l}\mathbf{N} \\
\mathbf{0}\end{array}$ & $\begin{array}{c}\text { Program } \\
\text { Manajemen }\end{array}$ & Kondisi Sekarang & Kondisi ke Depan \\
\hline 1 & $\begin{array}{c}\text { Pengelolaan } \\
\text { Dana }\end{array}$ & $\begin{array}{l}\text { Pemerintah daerah Kabupaten } \\
\text { Tanggamus sebenarnya } \\
\text { mendukung upaya peningkatan } \\
\text { pertasi olahraga tetapi dengan } \\
\text { tersedianya dalam Anggaran } \\
\text { Pendapatan Belanja Daerah } \\
\text { (APBD) Kabupaten untuk } \\
\text { membiayai pembinaan cabang } \\
\text { olahraga tidak terlalu besar dan } \\
\text { bisa dikatakan minim. }\end{array}$ & $\begin{array}{l}\text { Tersedianya dana yang cukup } \\
\text { memadai, hal ini dikarenakan } \\
\text { keberadaan sebuah organisasi } \\
\text { olahraga pada dasarnya } \\
\text { membutuhkan dana yang cukup } \\
\text { besar dalam operasionalnya. } \\
\text { Manajemen kegiatan pengelolaan } \\
\text { dana yang dimiliki oleh suatu } \\
\text { perusahaan atau organisasi, yaitu } \\
\text { meliputi kegiatan pencarian, } \\
\text { pengelolaan dan penyimpanan } \\
\text { dana. Tujuan terdapatnya } \\
\text { manajemen keuangan adalah } \\
\text { untuk memaksimalkan nilai } \\
\text { organisasi. }\end{array}$ \\
\hline
\end{tabular}

\begin{tabular}{lccl}
\hline $\mathbf{N}$ & Program & Kondisi Sekarang & Kondisi ke Depan \\
\hline
\end{tabular}




\begin{tabular}{|c|c|c|c|}
\hline 2 & $\begin{array}{c}\text { Sarana dan } \\
\text { Prasarana }\end{array}$ & $\begin{array}{l}\text { Pengadaan sarana dan } \\
\text { prasarana basket sangat } \\
\text { minim dikarenakan anggaran } \\
\text { yang minim sehingga } \\
\text { membuat program } \\
\text { pembinaan sangat terhambat } \\
\text { dan pengurus menjadi tidak } \\
\text { bersemangat dalam membuat } \\
\text { program pembinaan secara } \\
\text { terprogram, bagaimana tidak } \\
\text { pengajuan sarana dan } \\
\text { prasarana bola basket sangat } \\
\text { jauh dari realisasi yang ideal. }\end{array}$ & $\begin{array}{l}\text { Invetaris dan pemeliharaan } \\
\text { adalah kegiatan melaksanakan } \\
\text { penggunaan, penyelenggaraan, } \\
\text { pengaturan dan pencatatan } \\
\text { barang-barang, menyusun daftar } \\
\text { barang yang menjadi milik } \\
\text { PERBASI Tanggamus ke dalam } \\
\text { satu daftar inventaris serta } \\
\text { kegiatan merawat, memelihara } \\
\text { dan menyimpan barang-barang } \\
\text { sesuai dengan bentuk-bentuk } \\
\text { jenis barangnya sehingga barang } \\
\text { tersebut awet dan tahan lama. }\end{array}$ \\
\hline 3 & Pelatih & $\begin{array}{l}\text { Di antara pelatih dan } \\
\text { pengurus tidak ada } \\
\text { kerjasama dan komunikasi } \\
\text { ini merupakan sebuah } \\
\text { kelemahan dari sistem } \\
\text { pembinaan serta secara } \\
\text { pembagian tugas kurang } \\
\text { jelas. Pembinaan terhadap } \\
\text { mutu pelatih telah dilakukan } \\
\text { dengan baik, dengan cara } \\
\text { penataran dan promosi, } \\
\text { tetapi dalam hal pembinaan } \\
\text { kurang perhatiannya }\end{array}$ & $\begin{array}{l}\text { Pemilihan pelatih di PERBASI } \\
\text { Tanggamus itu sudah ada kriteria } \\
\text { yang harus dipenuhi untuk } \\
\text { menjadi pelatih seperti harus } \\
\text { memiliki lisensi, membuat } \\
\text { program latihan, dan pengalaman } \\
\text { melatih yang cukup. Peran } \\
\text { pelatih di sini sangat kuat karena } \\
\text { dari penseleksian pemain serta } \\
\text { menjalankan program latihan itu } \\
\text { dilaksanakan oleh pelatih, hanya } \\
\text { sedikit pengaruh dari Pengkab } \\
\text { PERBASI Tangamus dalam hal } \\
\text { administrasi saja dan } \\
\text { mempercayakan semua kepada } \\
\text { pelatih untuk menjalankan proses } \\
\text { di lapangan. }\end{array}$ \\
\hline 4 & $\begin{array}{c}\text { Program } \\
\text { Latihan }\end{array}$ & $\begin{array}{l}\text { a. Kesulitan membuat program } \\
\text { latihan. } \\
\text { b. Materi yang diajarkan sesuai } \\
\text { kemampuan yang telah } \\
\text { dimiliki atlet. } \\
\text { c. Pelatih melaksanakan } \\
\text { program latihan sesuai } \\
\text { dengan pengalamannya } \\
\text { sebagai peserta/atlet basket } \\
\text { sebelumnya. } \\
\text { d. Pengetahuannya di dalam } \\
\text { kepelatihan masih kurang. } \\
\text { e. Waktu latihan yang kurang. }\end{array}$ & $\begin{array}{l}\text { Pelatih tim Tanggamus membuat } \\
\text { program latihan dengan baik dan } \\
\text { dijalan sesuai program yang } \\
\text { dibuat. program latihan dibuat } \\
\text { agar pemberian beban latihan } \\
\text { dapat menjadi sefisiologis } \\
\text { mungkin dan selalu dengan } \\
\text { keadaan yang baru yang } \\
\text { merupakan hasil pelatihan. } \\
\text { Dengan demikian peningkatan } \\
\text { beban latihan selalu berdasarkan } \\
\text { fakta objektif, jadi tidak } \\
\text { berdasarkan kira-kira saja. }\end{array}$ \\
\hline
\end{tabular}




\begin{tabular}{|c|c|c|c|}
\hline $\begin{array}{l}\mathbf{N} \\
\mathbf{0}\end{array}$ & $\begin{array}{c}\text { Program } \\
\text { Manajemen }\end{array}$ & Kondisi Sekarang & Kondisi ke Depan \\
\hline 5 & $\begin{array}{c}\text { Kepengurusa } \\
\text { n PERBASI } \\
\text { Tanggamus }\end{array}$ & $\begin{array}{l}\text { a. Pembinaan bola basket yang } \\
\text { dilakukan Pengkab masih } \\
\text { sangat terbatas jika } \\
\text { dipandang secara ideal. } \\
\text { b. Pengkab PERBASI } \\
\text { Tanggamus belum memiliki } \\
\text { program pembinaan jangka } \\
\text { panjang secara terencana. } \\
\text { c. Secara manajemennya sudah } \\
\text { cukup baik, dapat dilihat } \\
\text { kepengurusan di PERBASI } \\
\text { Tanggamus struktur } \\
\text { organisasinya lengkap. }\end{array}$ & $\begin{array}{l}\text { Pelaksanaan } \\
\text { kepengurusan di Kabupaten } \\
\text { Tanggamus semestinya berjalan } \\
\text { seiring dengan program } \\
\text { pembinaan yang dicanangkan } \\
\text { induk organisasi olahraga di } \\
\text { daerah tersebut. Peran jaringan } \\
\text { mencakup kerjasama antar } \\
\text { organisasi penting dalam } \\
\text { memfasilitasi perolehan sumber } \\
\text { daya }\end{array}$ \\
\hline 6 & Atlet & $\begin{array}{l}\text { a. Hanya sedikit perhatian dari } \\
\text { pengurus dalam pemberian } \\
\text { support terhadap atlet. } \\
\text { b. Seleksi pemain tidak } \\
\text { transparan dan terbuka. }\end{array}$ & $\begin{array}{l}\text { Pemilihan atlet harus mencakup } \\
\text { semua kriteria yang akan menjadi } \\
\text { penilaian yang terbaik untuk } \\
\text { menjadi atlet Pengkab PERBASI } \\
\text { Tanggamus. }\end{array}$ \\
\hline 7 & $\begin{array}{c}\text { Dukungan } \\
\text { Masyarakat }\end{array}$ & $\begin{array}{l}\text { Faktor dukungan lingkungan } \\
\text { hanya keluarga dalam } \\
\text { kelancaran pelaksanaan } \\
\text { pembinaan atlet. }\end{array}$ & $\begin{array}{l}\text { Saling kerjasama antar } \\
\text { masyarakat dan orang tua } \\
\text { merupakan dukungan yang } \\
\text { sangat penting serta semoga } \\
\text { terjalin semakin } \\
\text { hubungannya untuk kemajuan } \\
\text { Pengkab PERBASI Tanggamus. }\end{array}$ \\
\hline
\end{tabular}

Prestasi olahraga dapat dicapai apabila sistem pembinaan yang ada dapat direncanakan dan terlaksana dengan baik. Menurut Yunida (2017) menyatakan proses dalam pembinaan prestasi olahraga, memiliki banyak faktor yang perlu diperhatikan yang di antaranya tujuan pembinaan yang jelas, program latihan yang sitematis, materi dan metode yang tepat, memahami karakteristik atlet yang dibina baik secara fisik/psikologi, kemampuan pelatih, sarana prasarana dan kondisi lingkungan pembinaan. Pencapaian prestasi cabang olahraga tentunya tidak terlepas dari berbagai faktor, salah satunya adalah faktor kondisi fisik. Kondisi fisik merupakan pondasi dari prestasi olahraga sebab teknik, taktik dan mental akan dapat dikembangkan dengan baik jika memiliki kualitas fisik yang baik (Zhannisa \& Sugiyanto 2015). Dalam mendukung semua pencapaian prestasi maka harus ada model dalam sistem manajemen organisasi pemerintah dan pengurus PERBASI Tanggamus sebagai dasar pembibitan atlet. 


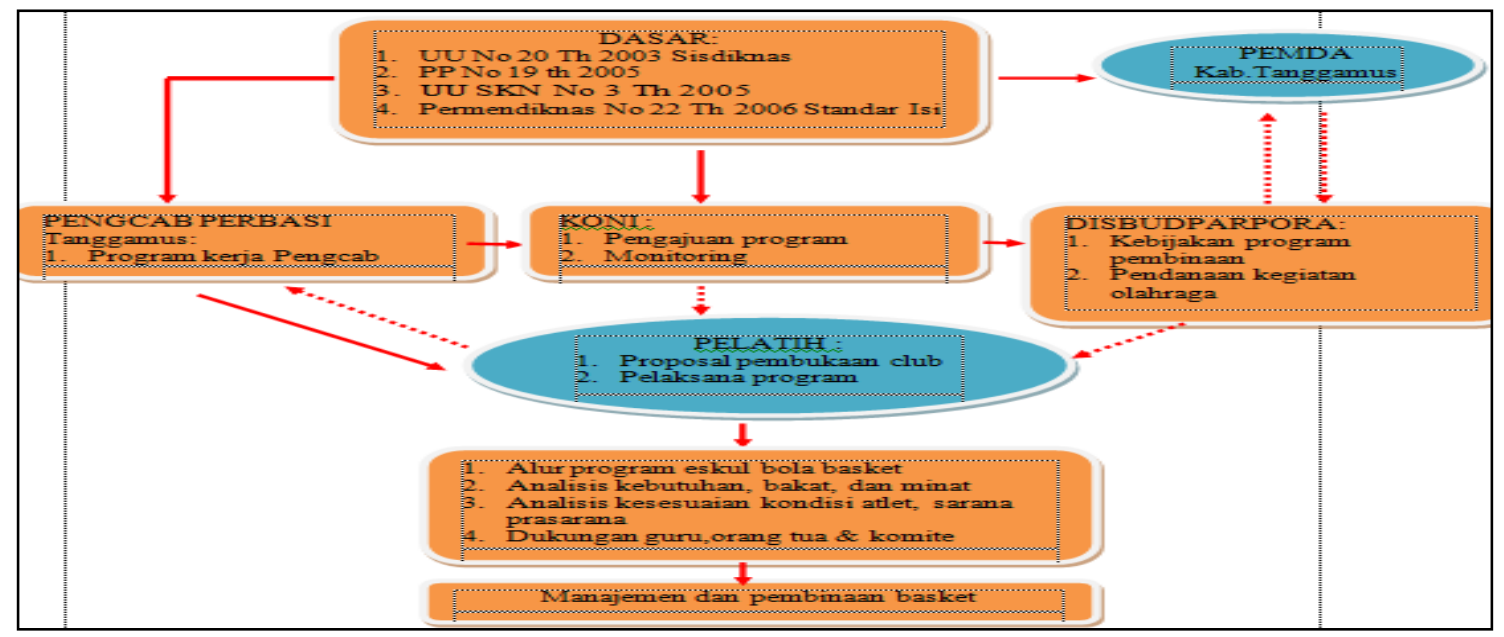

Gambar 1. Model Alternatif Sistem Manajemen Organisasi Pemerintah Sebagai Dasar Pembibitan Atlet Bola Basket di Kabupaten Tanggamus

Pengkab PERBASI Tanggamus masih memiliki kekurangan dalam manajemen dan pembinaan yang selama ini dijalankan, selanjutnya peneliti merekomendasikan model ideal sistem manajemen dan pembinaan bola basket sebagai dasar pembibitan atlet di Kabupaten Tanggamus.

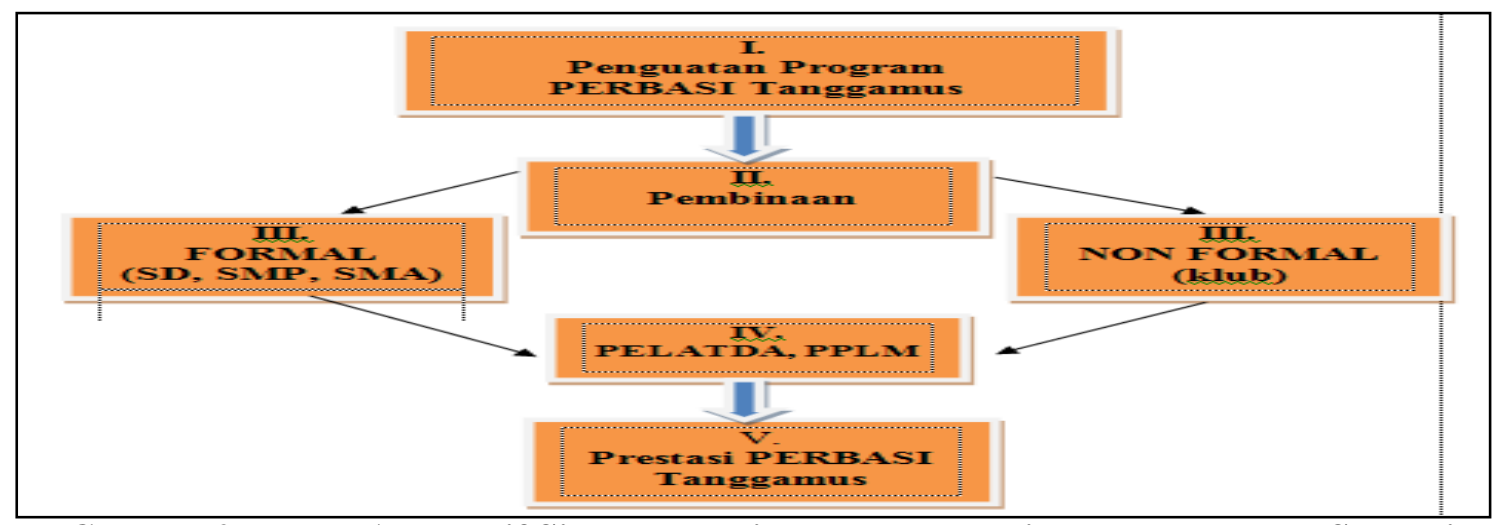

Gambar 2. Model Alternatif Sistem Manajemen dan Pembinaan Bola Basket Sebagai Dasar Pembibitan Atlet di Kabupaten Tanggamus

\section{KESIMPULAN}

Hasil penelitian ini menunjukan bahwa secara umum pendanaan untuk kegiatan Pengkab PERBASI Tanggamus dari APBD yang disalurkan melalui DISPARPORA Kabupaten Tanggamus dan proses penggalian dana belum dilaksanakan secara maksimal, sehingga mempengaruhi kegiatan yang dilaksanakan Pengkab PERBASI Tanggamus. Manajemen sarana dan prasarana, sarana latihan yang digunakan Pengkab PERBASI Tanggamus untuk latihan bila dilihat dari aspek kualitas dan kuantitas belum memadai. Manajemen Pelatih yang ada bila dilihat dari kualifikasi yang dimiliki dan pengalaman dibidang olahraga bola basket sudah cukup baik dan telah memenuhi syarat sebagai 
seorang pelatih. Manajeman program latihan pelaksanaan yang diberikan pelatih dilakukan secara berjenjang dan berkesinambungan. Manajemen kepengurusan, susunan pengurus yang ada belum bisa dikatakan solid dan berhasil dan belum mengalami suatu perubahan yang berarti, karena sampai dengan saat ini hanya beberapa kepala bidang yang menjalankan bahkan merangkap tugas dari kepala bidang pembinaan lain. Manajemen atlet secara umum proses rekrutmen atlet sudah berjalan baik karena penseleksian diambil dari beberapa klub yang ada dan dilakukan pemantauan perkembangan atlet. Dukungan masyarakat, terutama sekali dukungan dan peran orang tua atlet dalam mendukung kemajuan prestasi Pengkab PERBASI Tanggamus. Hasil penelitian ini dapat menjadi bahan evaluasi dan masukan bagi pengurus, pelatih, maupun atlet dalam proses pembinaan prestasi bola basket di Kabupaten Tanggamus ke depan.

Hasil penelitian ini menunjukkan masih adanya beberapa indikator yang belum maksimal dan menjadi permasalahan. Atas dasar tersebut, hasil penelitian ini dapat dijadikan sebagai penelitian pendahuluan yang nantinya menjadi dasar pelaksanaan penelitian selanjutnya dalam lingkup pembinaan prestasi prestasi bola basket di Kabupaten Tanggamus Provinsi Lampung.

\section{DAFTAR PUSTAKA}

Beraan, S. L. T., Karim, A., \& Irawan, B. (2019). Manajemen Pembinaan Olahraga Prestasi Komite Olahraga Nasional Indonesia (KONI) Provinsi Kalimantan Timur. EJournal Administrative Reform, 7(4), 450-458.

Carkanji, V., \& Bozo, D. (2012). Technology Utilization In Higher Education And In Sport Management Teaching. In International Christmas Sport Scientific Conference (pp. 202-207). Szombathely, Hungary: International Network of Sport and Health Science. https://doi.org/10.4100/jhse.2012.7.Proc1.23

Dongoran, M. F., Kalalo, C. N., \& Syamsudin, S. (2020). Profil Psikologis Atlet Pekan Olahraga Nasional (PON) Papua Menuju PONXX Tahun 2020. Journal Sport Area, 5(1), 13-21. https://doi.org/10.25299/sportarea.2020.vol5(1).4621

Handoko, T. H. (2011). Manajemen. BPFE Yogyakarta.

Laksana, G. (2017). Perspektif olahraga petanque dalam mendukung prestasi olahraga Jawa Tengah. Journal of Physical Education and Sports, 6(1), 2502-4477.

Miles, M. B., Huberman, A. M., \& Saldana, J. (2014). Qualitative Data Analysis, A Methods Sourcebook (Edisi Ke-3). Sage Publications.

Misener, K., \& Doherty, A. (2013). Understanding capacity through the processes and outcomes of interorganizational relationships in nonprofit community sport organizations. Sport Management Review, 16(2), 135-147. https://doi.org/10.1016/j.smr.2012.07.003

Muryadi, A. D. (2015). Evaluasi Program Pembinaan Sepakbola Klub Persijap Jepara. Jurnal Ilmiah PENJAS, 1(2), 1-16. 
Muslima, T. F., \& Himam, F. (2018). Peran Pelatih dalam Pembinaan Prestasi Atlet pada Organisasi Taekwondo Profesional. Gadjah Mada Journal of Professional Psychology, 2(3), 186-199.

Nugraha, P. D., \& Pratama, E. B. (2019). Survei Pembinaan Prestasi Atlet Bolabasket Kelompok Umur di Bawah 16 dan 18 Tahun Pada Tim Bolabasket Kota dan Kabupaten Madiun Tahun 2018. Journal Sport Area,4(1), 240-247. https://doi.org/10.25299/sportarea.2019.vol4(1).2394

Rachmawati, R. I., Kriswantoro, K., \& Nasution, M. (2019). Manajemen Klub Golf Semarang Olympic Golf Club (SOGC) Kota Semarang Tahun 2017. Journal of Sport Coaching and Physical Education, 4(1), 21-27.

Ramadan, G., \& Iskandar, D. (2018). Pengaruh Gaya Mengajar dan Motivasi Belajar Terhadap Hasil Belajar Lay Up Shoot. Jurnal Pendidikan Edutama, 5(1), 91-100. http://dx.doi.org/10.30734/jpe.v5i1.133

Robertson, J., Eime, R., \& Westerbeek, H. (2018). Community sports clubs: are they only about playing sport, or do they have broader health promotion and social responsibilities?. Annals of Leisure Research. 22(2), 215-232. https://doi.org/10.1080/11745398.2018.1430598

Rumini. (2015). Manajemen Pembinaan Cabang Olahraga Atletik di Pusat Pendidikan dan Latihan Pelajar (PPLP) Provinsi Jawa Tengah. Journal of Physical Education Health and Sport, 2(1), 20-27. https://doi.org/10.15294/jpehs.v2i1.3938

Schaillee, H., Spaaij, R., Jeanes, R., \& Theeboom, M. (2019). Knowledge Translation Practices, Enablers, and Constraints: Bridging the Research-Practice Divide in Sport Management. Journal of Sport Management, 1(3), 366-378. https://doi.org/https://doi.org/10.1123/jsm.2018-0175

Saputra, A. F. D., \& Subagio, I. (2016). Manajemen Pembinaan Prestasi KONI Kabupaten Tuban. Jurnal Prestasi Olahraga, 1(1), 1-17.

Swierzy, P., Wicker, P., \& Breuer, C. (2019). Usefulness of multilevel modeling in sport management research: The case of voluntary roles in nonprofit sports clubs. Measurement in Physical Education and Exercise Science, 23(4), 325-336. https://doi.org/10.1080/1091367X.2018.1438289

Ulum, A. S., Setyawati, H., \& Yuwono, C. (2013). Pembinaan olahraga bela diri wushu di Kota Salatiga tahun 2013. Journal of Physical Education, Sport, Health and Recreations, 2(10), 624-629. https://doi.org/10.15294/active.v2i10.2017

Undang-Undang Republik Indonesia. (2005). Sistem Keolahragaan Nasional. Presiden Republik Indonesia.

Wani, B. (2018). Evaluasi Program Pembinaan Prestasi Cabang Olahrga Tinju Pada Pusat Pembinaan dan Latihan Olahraga Pelajar (PPLP) Provinsi Nusa Tenggara Timur. Jurnal Ilmiah Pendidikan Citra Bakti, 5(1), 35-43. 
Wen, X. (2015). A Study on Sports Training Management System of Some Universities in Chengdu. In Internasional Conference on Civil, Materials and Environmental Sciences (CMES) (pp. 305-307). Atlantis Press. https://doi.org/10.2991/cmes15.2015 .85

Yunida, E., Sugiharto, S., \& Soenyoto, T. (2017). Manajemen Pembinaan Merdeka Basketball Club (MBBC) Pontianak Kalimantan Barat Tahun 2016. Journal of Physical Education and Sports, 6(2), 2502-4477.

Yusfi, H., \& Mashuri, H. (2019). Evaluasi Program Pembinaan Tenis Lapangan Pelti Kota Palembang. Journal of Sport Science and Education, 4(1), 7-13. http://dx.doi.org/10.26740/jossae.v4n1.p7-13

Zhannisa, H. U., \& Sugiyanto, F. (2015). Model Tes Fisik Pencarian Bakat Olahraga Bulutangkis Usia di Bawah 11 Tahun di DIY. Jurnal Keolahragaan, 3(1), 117-126. https://doi.org/10.21831/jk.v3i1.4974 